\title{
The Importance of Acid-base Analysis in Dogs Whit Orthopedic Procedures Under General Anesthesia (P)
}

\author{
Cristian Paul POPOVICI ${ }^{1 *}$, Cosmin PESTEAN ${ }^{2}$,Razvan CODEA ${ }^{2}$, Gavril GIURGIU ${ }^{1}$, Constantin BODOLEA ${ }^{3}$, \\ Liviu OANA ${ }^{2}$ \\ ${ }^{1}$ Faculty of Veterinary Medicine, Department of Internal Medicine, University of Agricultural Sciences \\ and Veterinarian Medicine, Cluj-Napoca, 3-5, Mănăștur Street, 400372, Romania. \\ ${ }^{2}$ Faculty of Veterinary Medicine, Department of Anesthesiology and Surgical Techniques, University of \\ Agricultural Sciences and Veterinarian Medicine, Cluj-Napoca, 3-5, Mănăștur Street, 400372, Romania. \\ ${ }^{3}$ Faculty of human medicine, Department of Anesthesia and Intensive Therapy, of Medicine and \\ Pharmacy" Iuliu Hateganu, . \\ * Corresponding author e-mail: popovici_vet@yahoo.com
}

Bulletin UASVM Veterinary Medicine 71(2) / 2014,

Print ISSN 1843-5270; Electronic ISSN 1843-5378

DOI:10.15835/buasvmcn-vm: 10797

Keywords: anesthesia, blood gases, dog

Introduction. Venous blood gases analysis provides information on acid-base status and ventilation (venous partial pressure of $\mathrm{CO} 2$ ) (Reiss, 2009). General anesthesia reduces the oxygenation degree of blood (Grimm, 2010), and SpO2 analysis by transcutaneous monitor does not approximate correctly the level of oxygenation from the patient's body (Barter, 2011).

Material and methods. This study was performed on five canine patients (different breed, with ages between 4 months to 11 years, 3 males and 2 females), scheduled for femoral head resection procedures. A balanced anesthesia protocol was performed: induction - propofol (Propofol 1\%, 20 ml, "Fresenius", Kabi Deutchland $\mathrm{GmbH}$, Germany) to effect, maintenance sevoflurane 2,5\% (Sevofluran $250 \mathrm{ml}$, Abbott Laboratories Ltd, U. K.); - analgesia with fentanyl $3 \mu \mathrm{g} / \mathrm{kg}$ b.w.- bolus (Fentanyl-Richter $5 \mathrm{ml}, 50 \mu \mathrm{g} /$ $\mathrm{ml}$ ) followed by CRI $5 \mu \mathrm{g} / \mathrm{kg}$ b.w./min (Braun Perfusor FM- infusion pump), miorelaxation rocuronium 0,4 mg/kg b.w. (Rocuronium Kabi 10 $\mathrm{mg} / \mathrm{ml}$ 10ml, S.C.Fresenius Kabi Romania) bolus. The patients were endotrachealy intubated and mechanical ventilation was started (IPPV) - 15 mbar, $15 \mathrm{ml} / \mathrm{kg}$ b.w., 15 breaths/min (Dräger Cato VT 20 anesthesia machine). Ventilator parameters were adjusted in conformity with $\mathrm{ETCO}_{2}$ values during the surgical procedures.Blood gases analysis was performed from venous blood $\left(\mathrm{pH}, \mathrm{PCO}_{2}\right.$, $\mathrm{HCO}_{3}^{-}$, BEecf) using GEM Premier 2000 blood gas analyzer, in different times (-1- before induction, 0 - following induction and before administration of NMB, 15 - after NMB administration, 60 minutes and 120 minutes after induction). The collection of the blood samples was performed in heparinated syringe (Blood sample for Blood Gas with cone cap" $2 \mathrm{ml}$, Instrumentation Laboratory) exactly to the signs.

Results and discussions. In all of our cases anesthesia induced respiratory acidosis $\mathrm{pH}$ under 7.35, $\mathrm{PvCO}_{2}$ higher than $46 \mathrm{mmHg}$ ).

Tab. 1. Values of $\mathrm{pH}$ in dogs under general anesthesia

\begin{tabular}{cccccc}
\hline $\begin{array}{c}\text { Casenumber/ } \\
\text { time }\end{array}$ & Case 1 & Case 2 & Case 3 & Case 4 & Case 5 \\
\hline-1 & 7.52 & 7.38 & 7.4 & 7.37 & 7.35 \\
0 & 7.46 & 7.31 & 7.38 & 7.28 & 7.27 \\
15 & 7.24 & 7.29 & 7.27 & 7.22 & 7.31 \\
60 & 7.29 & 7.27 & 7.26 & 7.31 & 7.25 \\
120 & 7.3 & 7.31 & 7.3 & 7.3 & 7.34 \\
\hline
\end{tabular}

Note: Normal values in dogs': 7,35-7.45(Ress, 2009) 
Tab. 2. Values of $\mathrm{PvCO}_{2}$ in anesthesia dogs (venous blood)

\begin{tabular}{cccccc}
\hline $\begin{array}{c}\text { Casenumber/ } \\
\text { time }\end{array}$ & Case 1 & Case 2 & Case 3 & Case 4 & Case 5 \\
\hline-1 & 27 & 42 & 38 & 40 & 45 \\
0 & 26 & 49 & 37 & 45 & 55 \\
15 & 56 & 53 & 48 & 51 & 50 \\
60 & 48 & 55 & 50 & 42 & 56 \\
120 & 45 & 50 & 52 & 50 & 45 \\
\hline
\end{tabular}

Note: Normal values: PvCO2:40-46 mmHg (Ress, 2009)

Tab. 3. $\mathrm{HCO}_{3}^{-}$values under general anesthesia

\begin{tabular}{cccccc}
\hline $\begin{array}{c}\text { Casenumber/ } \\
\text { time }\end{array}$ & Case 1 & Case 2 & Case 3 & Case 4 & Case 5 \\
\hline-1 & 22 & 24.8 & 23.5 & 23.1 & 24.8 \\
0 & 18.5 & 24.7 & 21.9 & 21.1 & 25.3 \\
15 & 24 & 25.5 & 22 & 20.9 & 25.2 \\
60 & 23.1 & 25.3 & 21.9 & 21.1 & 24.6 \\
120 & 22.1 & 25.2 & 21.6 & 21.6 & 24.3 \\
\hline
\end{tabular}

Note: Normal values in dogs: $\mathrm{HCO}_{3}: 20-24 \mathrm{mmHg}$ (Ress, 2009)

Tab. 4. ETCO $_{2}$ values under general anesthesia

\begin{tabular}{cccccc}
\hline $\begin{array}{c}\text { Casenumber/ } \\
\text { time }\end{array}$ & Case 1 & Case 2 & Case 3 & Case 4 & Case 5 \\
\hline-1 & 46 & 45 & 32 & 33 & 44 \\
0 & 50 & 45 & 38 & 33 & 51 \\
15 & 42 & 43 & 42 & 40 & 38 \\
60 & 36 & 41 & 47 & 41 & 37
\end{tabular}

Note: Normal values in dogs: ETCO $_{2} 35-45 \mathrm{mmHg}$ (Ress, 2009)

Tab. 5. BEecf values under general anesthesia

\begin{tabular}{cccccc}
\hline $\begin{array}{c}\text { Casenumber/ } \\
\text { time }\end{array}$ & Case 1 & Case 2 & Case 3 & Case 4 & Case 5 \\
\hline-1 & -0.9 & -0.3 & -1.3 & -2.2 & -0.8 \\
0 & -5.3 & -1.6 & -3.2 & -5.6 & -1.6 \\
15 & -3.4 & -1.1 & -4.9 & -6.8 & -1.1 \\
60 & -3.5 & -1.6 & -6.8 & -5.2 & -2.6 \\
120 & -4.3 & -1.1 & -5.2 & -3.7 & -1.5 \\
\hline
\end{tabular}

Normal values in dogs: BEecf: -4 until $4 \mathrm{mEq} / \mathrm{L}$ ( Ress 2009)
There is not direct correlation between the values of pCO2 and ET CO2 (Tab.2 and 4)

Blood gases analysis performed from venous blood, revealed more accurate the changes in PvCO2 level, than the data obtained from ETCO2, what remained under $45 \mathrm{mmHg}$, in the majority of the cases and can be inaccurate in small body sized patients (Barter, 2011). This aspect is very important in adjusting the settings used in mechanical ventilation for the reduction of respiratory acidosis induced by hypoventilation under general anesthesia.

Conclusion. We recommend the use of blood gases analysis in general anesthesia, for correction of mechanical ventilation settings and prevention of respiratory acidosis.

\section{References}

1. Adam R., Irizarry R (2009). Arterial and Venous Blood Gases: induction, interpretations and clinical applications. Compendium 1-7

2. Dyson DH (2012). Positive pressure ventilation during anesthesia in dogs: Assessment of surface area derived tidal volume. Can Vet J 53: 63-66.

3. Grimm KA (2010). Arterial blood gas analysis and interpretation in small-animal practice. Proceedings Baltimore.

4. Barter LS, Hopper K (2011). Transcutaneous monitor approximates $\mathrm{PaCO} 2$ but not $\mathrm{PaO} 2$ in anesthetized rabbits. Vet Anaest and Analg 38:568-575. 